\title{
A Ilíada por Odorico Mendes: prólogo inédito da tradução
}

\author{
Raquel da Silva Yee ${ }^{1}$, Rosane de Souza, Ronaldo Lima
}

Resumo: Trata-se de explicitar o processo de investigação que nos conduziu a localizar, quase ao acaso, documento presumidamente desconhecido ou esquecido, porém peça essencial à recomposição de parte da história da tradução literária no Brasil. Mais que isso, o referido texto expõe fragmentos da visão de um importante tradutor sobre seu próprio ato tradutório. $\mathrm{O}$ autor, Manuel Odorico Mendes, expõe posições pessoais totalmente inéditas. A transcrição do prólogo manuscrito é apresentada na íntegra, trazendo à tona material de inestimável valor, por longos anos destacado de seu conjunto. O texto, que aqui se revela, constitui elo fundamental para a progressiva organização do imenso quebra-cabeça que os arquivos históricos disponibilizam aos pesquisadores dedicados, de modo geral, aos estudos da tradução literária no Brasil e, de modo singular, àqueles centrados nos estudos odoricianos.

Palavras-chaves: Prólogo inédito, Tradução da Ilíada, Odorico Mendes.

Raquel da Silva Yee e Rosane de Souza são mestrandas do Programa de Pós- graduação em Estudos da Tradução da Universidade Federal de Santa Catarina - PGET/UFSC, tendo como orientador o Prof. Dr. Ronaldo Lima. 
Raquel da Silva Yee, Rosane de Souza, Ronaldo Lima. A Ilíada por Odorico...

\section{O encontro com o prólogo manuscrito}

Em pesquisa realizada no mês de julho 2008, junto aos Arquivos do Museu Imperial de Petrópolis/RJ, inicialmente com vistas a acessar os manuscritos da tradução das Mil e uma Noites realizada por D. Pedro II, localizamos, entre os materiais catalogados sob a rubrica "Estudos do Imperador", documento cuja caligrafia se destacava no conjunto dos textos analisados. Exame preliminar revelou tratar-se da tradução da Ilíada, precedida por um prólogo sem data e tampouco assinatura do autor. $\mathrm{O}$ texto trazia uma série de discussões sobre Homero, bem como considerações sobre procedimentos tradutórios. Informações textuais apontaram para o nome de D. Militina Jansen Müller, irmã de Manuel Odorico Mendes. Este conjunto de questões, alinhadas, corroboraram a tese de que se tratava, efetivamente, de documento redigido pelo próprio Odorico Mendes.

Faz-se necessário destacar que a tradução da Ilíada de 1874 não apresenta o referido prólogo, nem tampouco o menciona. A versão de 2008, elaborada a partir da primeira, também não acrescenta nenhuma informação que remeta ao documento em questão. Contrariamente ao conteúdo do texto, Nienkötter afirma que "Odorico sequer toca na Questão Homérica em seus comentários" (Cf. HOMERO, Ilíada, 2008, p. 17). A literatura dedicada aos estudos odoricianos também não faz nenhuma referência, mesmo que indireta, à existência desse escrito ou ao seu conteúdo. Tais indícios levam a supor que os editores não tiveram acesso a esse material, ou que o mesmo não fazia parte da versão enviada para a publicação. ${ }^{2}$

Nos arquivos encontrou-se também requerimento ${ }^{3}$ de $\mathrm{D}$. Militina Jansen Müller solicitando a D. Pedro II devolução dos ma-

2 Logo após a descoberta também recorremos, particularmente, ao grupo de pesquisadores da UNICAMP, notadamente ao Prof. Dr. Paulo Sergio de Vasconcellos que desenvolve pesquisas sobre as traduções de Odorico Mendes. O pesquisador nos informou não ter ciência do manuscrito original, mas tão somente da primeira edição traduzida da Ilíada, publicada em 1874, na qual não consta o referido Prólogo.

3 Requerimento arquivado na pasta de documentação do Arquivo Histórico do Museu Imperial de Petrópolis - RJ (Maço 160-Doc. 7415). 
nuscritos do irmão que supomos serem os mesmos que lá se encontram entre os "Estudos do Imperador". Mesmo certos de que aquele documento é de autoria do tradutor Odorico Mendes e que constitui um prólogo à tradução da Ilíada, restam dúvidas sobre as eventuais razões para não ter sido publicado na edição de 1874 .

Naturalmente, algumas hipóteses podem ser levantadas. Podese perguntar, por exemplo, se estaríamos diante de adendo exclusivamente dirigido ao Imperador, visando satisfazer seu prazer de leitura, não constando, pois, de outras eventuais cópias da mesma tradução. Considerando a possibilidade de haver mais de um manuscrito da tradução da Ilíada, seria aquela cópia a única acompanhada de um prólogo, uma vez que, segundo Lacombe (1989), o tradutor tinha o hábito de reproduzir cópias de seus trabalhos para enviar aos amigos?

Mediante as discussões que tratam do paradeiro dos manuscritos de Odorico Mendes, talvez algumas informações estejam em desacordo, pois segundo Leal (1987:53), o Imperador teria restituído os manuscritos à irmã do tradutor em 1872. Assim, dois anos antes da publicação da Ilíada, D. Militina já os teria em mãos.

Polêmicas lançadas à discussão, o que nos resta, como dado concreto, é que o referido achado constitui importante material de estudo para os pesquisadores em tradução e literatura brasileira. Catalogado como documento pertencente a D. Pedro II, sua localização científica exigiria considerável empenho. Tal descoberta ocorreu quase que ao acaso, em função das investigações direcionadas aos trabalhos realizados pelo Imperador, ele mesmo dedicado à prática tradutória e interessado em trabalhos afins, como este que aqui se apresentará.

\section{A Ilíada por Odorico Mendes}

Humanista, jornalista polêmico, político e literato, o maranhense Manuel Odorico Mendes (1799-1864) fez parte do círculo literário dos autores pré-românticos do século 19, tornando-se personalida- 
Raquel da Silva Yee, Rosane de Souza, Ronaldo Lima. A Ilíada por Odorico...

de marcante nos acontecimentos políticos, sociais e culturais desde o Primeiro Reinado. Foi admirador da literatura da antiguidade clássica e o primeiro brasileiro a traduzir na íntegra as obras poéticas virgilianas e as epopéias homéricas para o português.

Em meados do século 19, Odorico Mendes viu-se diante de grande desafio: traduzir mais 15 mil versos da "Ilíada de Homero". O tradutor dedicou anos de estudos para verter os episódios lendários da guerra entre os gregos e troianos, enfrentando questões de ordem linguística, cultural e pessoal. No decorrer do processo de tradução da Ilíada, Odorico Mendes mantinha correspondências com o amigo Paulo Barbosa, mordomo imperial. Escrevia-lhe sobre a vida em Paris e, notadamente, sobre o andamento de suas traduções, além de relatar fatos de sua vida pessoal, tal como sua dedicação aos filhos e as dificuldades financeiras que enfrentava para a manutenção da família na Europa. A amizade com o mordomo e a carreira política rendeu-lhe relações com a família imperial, em especial com D. Pedro II. O imperador, amante das letras e dedicado à prática tradutória, manifestava profundo interesse pelas traduções de Odorico Mendes e tinha o hábito de compará-las com as traduções que realizava (Cf. LACOMBE 1989).

Lançamos aqui os primeiros comentários sobre o referido prólogo, inclusive tocando nos alicerces da história da tradução literária, uma vez que algumas informações sobre Odorico Mendes precisarão ser complementadas. Trata-se, pois, de disponibilizar aos pesquisadores odoricianos observações embrionárias sobre o prólogo da Ilíada, sobre o seu método de tradução e sobre suas impressões a respeito da vida de Homero. Para fazê-lo, apresentamos na íntegra as considerações registradas no referido manuscrito, tal como seguem nas linhas abaixo. 


\section{Prologo}

Acabada a publicação do meu Virgílio, cogitei a maneira de não ficar ocioso. He mui provavel que não me lembrasse da Ilíada se minha irmã do lado materno D. Militina Jasen Müller, apaixonada de Homero que lera em francez, assim não me dicesse: "Depois de teres traduzido Virgilio, ou compõe obra tua, ou traduze a Iliada." Quanto a compor obra minha, sei bem que a um homem de sessenta annos já falta imaginação, e que tudo que eu produzisse, a não ser inteiramente insípido, seria medíocre; e de poesias mediocres ha excessiva quantidade. Quanto a Ilíada, havia eu a desgraça de saber quasi nada do grego, pois do pouco aprendido em Coimbra tinha me esquecido a maior parte. Consultei um amigo hellenista, e elle sinceramente achou a empresa mũito acima das minhas forças. Porem minha irmã insistiu, animou-me a estudar o grego, e eu lancei-me a Homero. A repugnancia em reaprender verbos, dialectos e tantas miudezas, desalentou-me; mas, sempre instado, adaptei o methodo que vou expôr.

Como distinguia ainda se o que se me aprensentava era verbo ou outra parte da oração, procurava todas as palavras gregas nos diccionarios, e guiado pela interpretação latina, alinhavava a minha versão; depois consultava as de Mme. Dacier, Bigman, Rochefort, Giguet, Salvini, Manti, Mancini e outros, e se alguma dellas me advertia de qualquer falta ou esquecimento, reformava a minha, tornando a consultar o original, a interpretação latina, commentadores etc. Isto me fazia marchar lentamente, $e$ houve dia que apenas apurava oito ou dez versos. Quando, com este methodo, consegui os tres primeiros livros, li-os ao mencionado hellenista, que he o Sr Joaquim Caetano da Silva; e elle, tendo-as combinado com o texto, animou-me a continuar. Para conseguir o meu intento, escolhi a residência de Pisa: nesta cidade quasi morta, onde em dous annos só convivi com a gente em cuja casa pagava a minha pensão, e com uma família cuja amisade era já de Paris, achando-me sem a menor distracção, tive tempo de meditar e escrever, e em quinze mezes obtive o dobro do que obtivera em Paris em dous annos e meio, concluindo a presente versão.

He uma regra já assentada que deve o traductor saber igualmente a lingua original e a sua; mas eu opino que, se lhe basta saber a do original

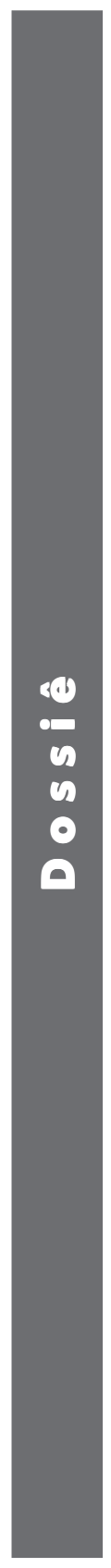


Raquel da Silva Yee, Rosane de Souza, Ronaldo Lima. A Ilíada por Odorico...

como um, forçoso the he saber a propria em dobro ou tresdobro. Quando se me apresentar, v.g., um trecho de versos, ainda que não conheça todas as palavras, posso buscál-as nos diccionarios, consultar comentadores, críticos etc.; mas os termos da propria língua, se não vem immediatamente á nossa memoria, como he que os havemos de procurar? Para bem traduzirmos em português, cumpre d'antemão e com afinco termol-o estudado, conhecer em grande parte os vocabulos; afim que nos occorram immediatamente e sem custo. Exemplo que ofereço nesta versão da Ilíada, prova a opinião acima exposta; e com igual methodo, jamais amestrado pela prática e pela experiencia, espero tambem verter a Odysséa, se a morte não vier atalhar projectos concebidos na minha idade.

\section{Brevissima noticia de Homero}

Sendo esta a primeira vez que em nossa língua apparece Homero sem ser em fragmentos, cumpre dar aos leitores algumas noções concernentes ao poeta maior da alta antiguidade. Se eu emprehendesse uma completa biographia, discutindo as questões que se tem levantado, assim do merito de suas obras, como do quando e onde nasceu, ou se nasceu, porque até da sua existencia duvidão mũitos; isso me levaria sobejo tempo, e seria grossissimo o volume onde na verdade não faria mais que daqui e dalli copiar trabalhos alheios, com mais ou menos disfarce, para ostentar erudição. Contento-me com esta brevissima noticia.

He constante que a honra de lhe dar o berço foi disputada por sete cidades, cujos nomes vem consignados nos Lusiadas pelo seguinte modo:

Esse que bebeu tanto da agua Aonia

Sobre quem tem contenda peregrina

Entre si Rhodes, Smyrna, e Colophonia

Athenas, Chios, Argo e Salamina.

Mas os modernos, com presumpção de saber tudo e emendar e destruir as opiniões recebidas, entraram em liça: Franceses, Inglezes, Italia- 
nos, Alemães e outros, cada um lhe creou uma pátria e Homero começou a ser do Egypto, de Nápoles, da Escossia e de Nenhures. Eu porem sou de voto que elle existiu e que provavelmente nasceu em Smyrna: Chio, que ao depois tem mais direito de reclamal-o, funda-se em dizer Homero, em um dos hymnos que era habitante daquela ilha; mas um homem pode habitar num paiz sem ter ahi nascido, e o mesmo texto he contra producentem, porque, se dali fosse, diria Sou de Chio e não Habito em Chio. Ha uma objecção a Smyrna, e he que, se fosse desta cidade, era Asiático, e não decantaria a guerra de Troia, que he na Ásia e foi venciada pelos Europeus. Ao que se responde que no tempo de Homero Smyrna era colonia de Achens, e elle se considerava como Grego. O certo eh que, no catalogo dos que ajudavam Troia, não se falla de Smyrna: a guerra não era propriamente entre Europeus e Asiaticos; era entre os Gregos e os Troianos com seus alliados.

Quanto a época em que floreceu, nada se pode affirmar precisamente; mas parece, pelo testemunho dos marmores de Arundel, que elle viveu pouco menos de três seculos depois da guerra de Troia. Wood o fasia mũito vizinho a esta guerra; opinião insustentavel á vista dos argumentos de Pope $e$ de outros. Um desses argumentos he que o poeta na Ilíada, invocando as Musas, pede que o inspirem, porque elle nada sabe senão pela fama e pela tradição; prova de que nem em menino tinha conhecido um velho do tempo da mesma guerra. Outro argumento he dizer na Ilíada que Ajax atirou facilmente uma pedra que nem dous homens do tempo do poeta poderiam mover: ora, se he que a raça humana degenera e diminue de forças, he gradualmente, e a diminuição de que se trata he tal, que suppõe o intervallo de alguns seculos. Bem que a epoca apontada pareça mais provavel, estou que a duvida continuará sempre a este respeito. Apenas se devem mencionar as extravagantes conjecturas do Inglez Cortar, o qual opinava que Homero e Hesíodo viviam 380 annos depois de Christo! Posto que os Inglezes, bem como os Allemães, sejam dotados de mũito espirito e tenham entre si autores sapientissimos, nelles he que se encontra o maior numero destas aberrações.

Mas, pondo de parte os modernos, e apegando-nos aos escritos mais chegados á epoca de Homero, vejamos o que tem sido espalhado e acreditado ácerca da sua vida.

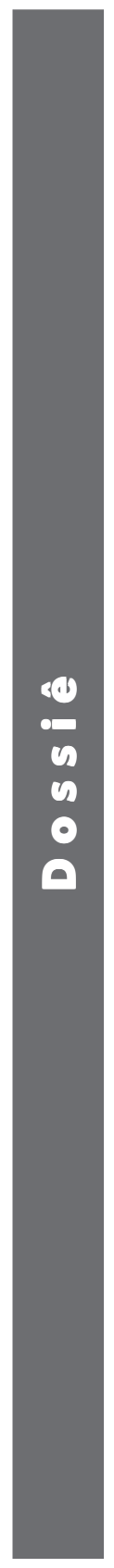


Raquel da Silva Yee, Rosane de Souza, Ronaldo Lima. A Ilíada por Odorico...

Menalippo de Magnesia se estabeleceu em Cumas na Jonia, onde casou e teve por filha Chriteida, que orphã cahiu sob a tutela de um tio seu ou simplesmente de um amigo de Menalippo. O tutor abusou da pupila, e para occultar-se, mandou-a gravida com Ismenia, que para Smyrna conduzia uma colonia. Chriteida, estando em uma festa celebrada á margem do rio Meles, alli pariu Homero, que por aquella circunstancia foi chamado Melesigenes. A mãe ao depois separou-se de Ismênia, foi obrigada a fiar lã para poder sustentar seu filho. O bom Phemio, que em Smyrna tinha uma escola de musica e de boas letras, enamorou-se della, casou-se, adouptouthe o filho, em que foi descobrindo felis indole e grandissimo ingenho. Mortos Phemio e Chriteida, succedeu Melesigenes na escola do pae, e adquiriu uma estrondosa reputação, dentro e fóra de Smyrna.

O capitão de um navio de Lencade, nomeado Mentes, amigo da poesia e instruido, affeiçoou-se a Melesigenes, fel-o deixar a escola e acompanhar em suas viagens. O jovem então já meditava a sua Ilíada, abraçou com prazer a ocasião de correr terras e ver os lugares e os costumes de que tinha de fallar. Tendo visitado a Itália e a Hespanha, foi- se a Ithaca, onde padeceu uma gravíssima ophthalmia: sendo porem assistido por Mentor, homem rico e hospitaleiro, em casa deste houve mũitas informações da vida de Ulysses. Já curado reembarcou-se com Mentes para Colophonia; mas, recahindo, a inflamação de olhos foi fatal, que veio a cegar inteiramente. Esta infelicidade o resolveu a tornar para Smyrna, e ahi terminou a Ilíada. Parece que seus compatriotas (desgraça quase infallivel dos homens de gênio, ou mesmo de simples talento) fartaram-no de louvores, mas deixaram-no em verdadeira miseria. Advirto porem que mũitos duvidam da sua cegueira.

Andou-se a Cumas, a ver se era melhor acolhido; no caminho, em um paiz dito Muro-Novo, um Tichio fabricante de coiraças o agasalhou com amor: dizem que até Herodoto nessa terra ainda se mostrava o lugar em que elle recitava seus versos: lá compos seus hymnos e outras poesias. Retornando a Cumas, foi primeiro bem recebido, depois com friesa, e finalmente com desprezo. Desde então he que Melesigenes começou a ser nomeado Homero, que uns opinam significar cego; outros cantor, e alguns refens. Passando-se á Phocea, um Testorides mestre de escola pediu-lhe que dei- 
xasse copiar os seus poemas; no que tendo consentido Homero para ter pão, fugiu Testorides para Chio, onde fez fortunas recitando como proprios os versos do pobre que vivia de esmola.

Constando a Homero tal impostura, embarcou-se para Chio num batel de pescadores, que o abandonaram na praia, onde passou a noite. Cego e sozinho, errou dous dias, e ao berrar de umas cabras, encaminhou-se para a parte donde vinham os sons; mas os rafeiros o teriam despedaçado, se the não acudisse o pastor que chamava-se Glauco. Este o introduzio na sua cabana; e, tendo-lhe Homero cantado seus versos em paga do bom agasalho, o pastor participou a seu amo esta aventura; e o amo, admirando aquelle cego extraordinario, confiou-lhe a educação de um filho. Testorides, que o soube tam vizinho, desappareceu. Homero sentou em Chio uma escola, e dessa vez lucrosamente recitava os seus poemas. Ahi adquiriu bens, casou-se e teve duas filhas; uma das quais morreu solteira, e a outra esposou um cidadão de Chio. Em Chio he que elle compos a Odysséa, onde inseriu os nomes de seus benfeitores, v.g. o de Phemio, o de Mentes e o de Mentor; assim como na Ilíada já tinha mencionado a Tichio. E ambicionando um theatro mais vasto á sua gloria, tentou ir- se para Athenas: aportou em Samas a Io, uma das Sporades; mas, quando estava de partida para Athenas, em Io adoeceu e morreu. Os habitantes o enterraram á borda do mar, segundo o costume de expôr os sepulcros dos homens celebres nos lugares mais publicos.

Esta narração he um resumo da Vida que em nome corre de Heródoto; a qual, ou seja do famoso historiador ou de outrem, he a mais acreditada, não obstante as objecções de mũitos, entre os quais figura Pope. Este, parecendo cuidar que só uma alta personagem he digna de cantar os heroes, diz que a Vida se refere a cousas da mais baixa condição e he indigna de Homero; $e$, o que he de notar em homem de tamanha intelligencia, trata com menoscabo o emprego de mestre de escola. Mas o seu compatriota Wood responde-lhe com razão que o emprego de mestre de escola, ou de musica, segundo se chamava então, he o que em nossos dias se diria um professor de encyclopedia, e que Homero não se devia dedignar de semelhante titulo. Acrescenta Wood que, ou seja de Heródoto ou não, embora contenha algumas inexactidões, a Vida possue mũitos caracteres de escrito antigo, e tem,

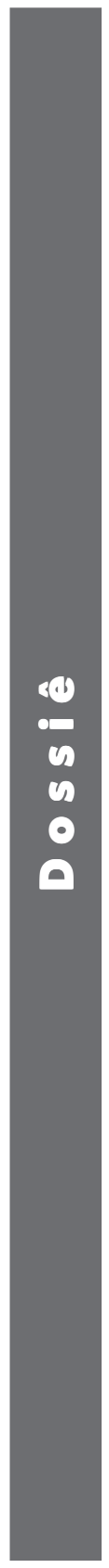


Raquel da Silva Yee, Rosane de Souza, Ronaldo Lima. A Ilíada por Odorico...

mais que outra qualquer, um grande ar de verdade, sendo despida de fabulas e desvio de imaginação.

Não deixarei de tocar no certame de Homero e Hesíodo, certame que, segundo os partidarios do ultimo, constava de uma inscripção, que existia em Chalcis, cujo sentido era que o poeta da paz e da economia domestica tinha jus mais sagrado á coroa do que o da guerra e da discordia. Mas, alem de que antigos e modernos crem provavel que um não foi contemporaneo do outro, he inadmissivel que Hesíodo houvesse occultado o nome do vencido, que fazia o maior brilho do seu triumpho. "Ser vencedor de Homero, exclama Cesarotti, não era naquelles tempos um titulo que invejaria o mesmo Apollo?"

Agora vamos ás suas obras. Sem tratarmos da Batrachomiomachia, ou guerra dos ratos e das rãs, nem dos hymnos que nos restam, que nem todos se crê serem de Homero, fallemos da Ilíada e da Odysséa. Para mim sam futeis e meros jogos de espirito os argumentos com que se pretende provar que Homero não existiu; que se engaram todos os que até lhe ergueram templos e altares; que toda antiguidade esteve no erro; que não sam delle as obras que the tem sido louvadas pela voz dos seculos; que a Ilíada e a Odysséa são mantas de retalhos; que tanto uma como outra foi composta por differentes pessoas e em differentes epocas, etc. etc. etc. Seria possivel que a Ilíada fosse de um poeta e a Odysséa de outro; mas he impossível que seja cada uma de mais de um autor, pela admirável connexão do seu todo. E parece bem que sam de um mesmo poeta; porque, apezar da mũitíssima differença de assumptos, acha-se em ambos os poemas um ar de parentesco inegavel. As repetições, de que se tem querido tirar prova contra- a unidade de taes obras, nada servem ao intento: os Asiaticos (notem-se os mesmos do Velho Testamento e ainda do Novo) gostavam de repetições; e esta, que hoje nos parece imperdoavel defeito, não o era naquelles tempos. Se ha um progresso entre a Ilíada e a Odysséa, isso não admira, porque uma foi parte da mocidade e outra da velhice; e Homero, que tinha o habito de observar e adquirir conhecimento, foi sempre augmentando os seus e enriquecendo a sua razão. Não me quero estender; basta-me declarar o que sinto sobre este ponto: a materia tem sido ampla e doutamente ventilada por mũitos, cujos livros comporiam uma não pequena biblioteca. 
Tanto sobre o lugar de nascimento e a vida de Homero, como sobre os seus escritos, o leitor curioso pode consultar Pope, Cesarotti, Mr. Bigman, o Marques de Fortia d' Urban; e quasi todos os traductores, mais ou menos, reflectem sobre as cousas relativas ao poeta. Escolhi os quatros apontados; porque elles, principalmente Cesarotti, entram em todas as particularidades, e citam ou combatem as varias opiniões: guiado por estes quatro, pode qualquer ter noticia e recorrer aos principaes, tanto aos que tratam a materia com o desejo de descobrir a verdade, como aos que, para ostentar ingenho e singularisar-se, dando tratos á imaginação, tem embrulhado tudo. Hoje andam nas mãos de todos os varos diccionarios historicos, faceis de consultar, onde se lê a biographia do poeta.

\section{Considerações finais}

Através das impressões de Odorico Mendes, torna-se possível circunscrever algumas de suas ideias sobre tradução, sobre o método adotado para desenvolvê-la. Evidenciam-se paralelamente as eventuais influências de outros autores que serviram de base para as reflexões apresentadas no prólogo sobre a vida de Homero e para composição da própria tradução.

Odorico Mendes manifesta algumas de suas posições enquanto tradutor. Por exemplo, afirma a importância do conhecimento e domínio amplo da língua alvo que, segundo ele, constitui a principal base para o êxito de uma tradução. Admite conhecer pouco da língua grega e, no entanto, realizou seu trabalho com êxito, recebendo críticas de todas as ordens, tal como aquela dos irmãos Campos que elogiam sua excelência. (Cf. MILTON, 1998, p. 205)

Os suportes adotados pelo tradutor se situam entre os mais apreciados no escopo da tradução da poesia épica, pois os conhecimentos revelados no prólogo e nos comentários que acompanham a tradução não se limitam a esclarecer e informar, muitas vezes ratificam enganos e discordam da interpretação de outros tradutores, revelando vasta cultura, que engloba a filologia, a história, a geografia, entre outras áreas do saber humano. Suas pesquisas envolve-

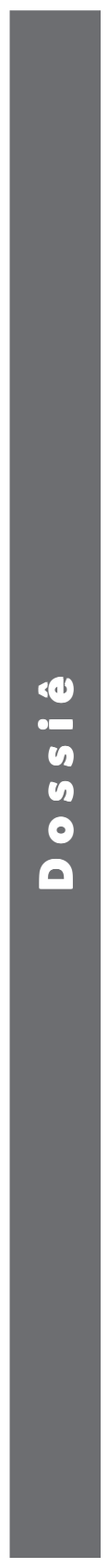


Raquel da Silva Yee, Rosane de Souza, Ronaldo Lima. A Ilíada por Odorico...

ram autores e textos redigidos em vários idiomas: inglês, francês, italiano. Alexander Pope, Mme Dacier, Melchiorre Cesarotti, e demais nomes citados são de tradutores que ao longo dos tempos despenderam valorosas discussões tradutológicas, mantendo-se ainda como referência no campo da literatura. (Cf. MANGUEL, 2008)

Finalmente, a "questão homérica", isto é, as indagações a respeito da autoria da Ilíada e da Odisséia, bem como as dúvidas sobre a própria existência do autor, não são recentes e ainda estão longe de serem exauridas. Ao mesmo tempo, é possível afirmar que os questionamentos e discussões apontados por Odorico Mendes, relativamente às investigações sobre as obras atribuídas a Homero são bem atuais, posto que o tema permanece aberto à discussão. Assim como outros teóricos, Odorico Mendes expõe sua versão dos fatos com base em seus estudos.

O texto inédito, aqui apresentado, constituiu peça destacada de seu conjunto durante longos anos. Doravante, se devidamente considerada por seu valor histórico e literário, poderá ser novamente agregada ao trabalho do autor. O texto, por ter permanecido desconhecido, carece de estudos minuciosos que certamente permitirão estabelecer conexões com a obra traduzida, bem como com suas notas, permitindo, provavelmente, uma melhor compreensão do trabalho integral de Odorico Mendes.

\section{Referências}

HOMERO, Ilíada: tradução Manuel Odorico Mendes, prefácio e notas verso a verso Sálvio Nienkötter. Cotia SP: Ateliê Editorial; Campinas, SP: Editora Unicamp, 2008.

HOMERO. Ilíada. Manuscrito da tradução de Manuel Odorico Mendes. [1863 ?]. Disponível no Arquivo Histórico do Museu Imperial de Petrópolis - RJ Doc.1077 maço 47. Acesso em 29 de julho de 2008.

LACOMBE, Américo Jacobina. Cartas de Manuel Odorico Mendes. Coleção Afrânio Peixoto. Rio de Janeiro: Academia Brasileira de Letras, 1989. 
LEAL, Antonio Henrique. Pantheon Maranhense. $2^{\underline{a}}$ ed. Rio de Janeiro: Alhambra, 1987.

MANGUEL, Alberto. Ilíada e Odisséia de Homero - Uma biografia. Tradução Pedro Maia Soares. Rio de Janeiro: Jorge Zahar Ed., 2008.

MILTON, John. Tradução: teoria e prática. 2. ed. São Paulo: Martins Fontes, 1998. 
Raquel da Silva Yee, Rosane de Souza, Ronaldo Lima. A Ilíada por Odorico...

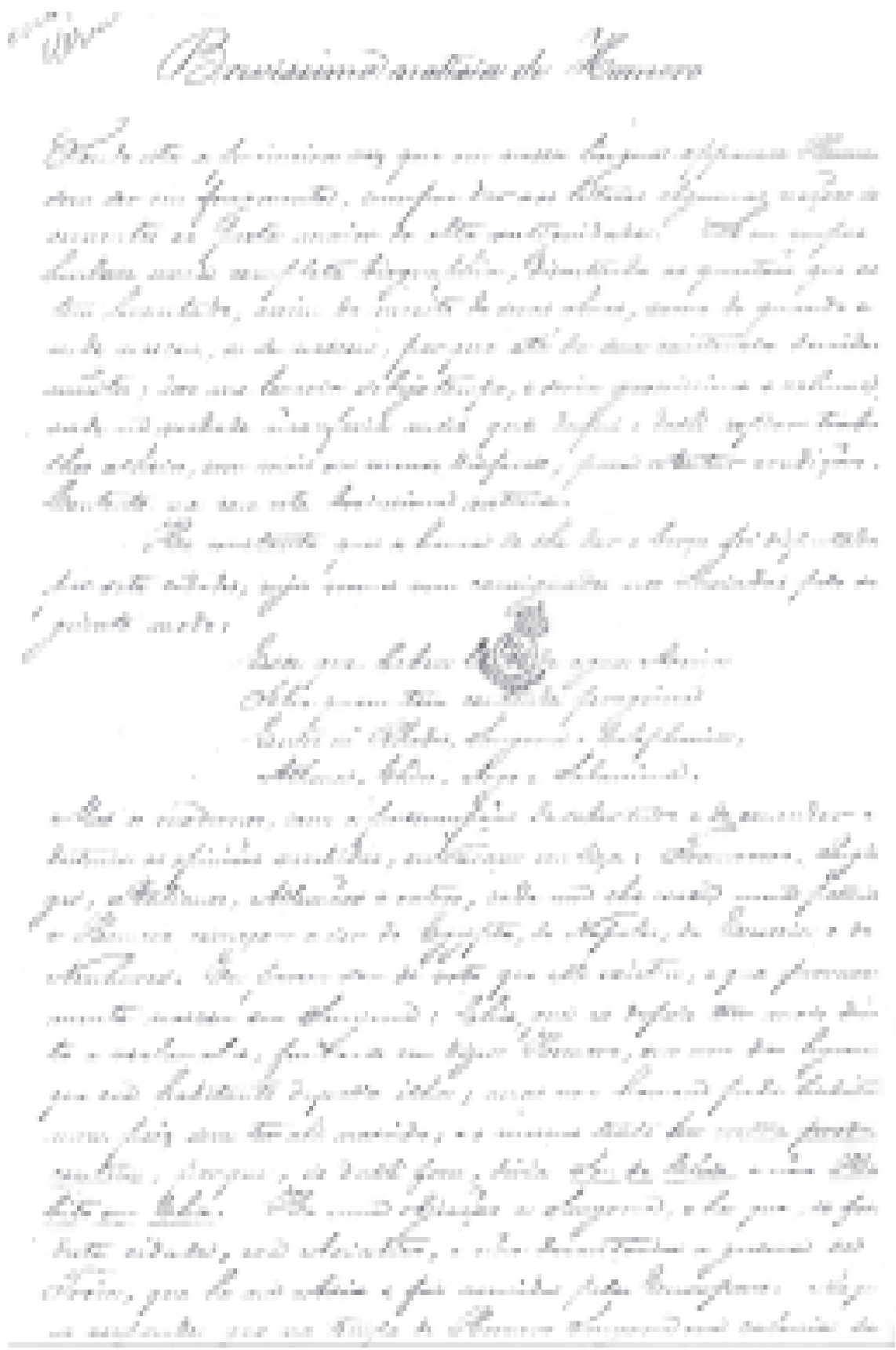

